\title{
Degrees of Canal Stenosis, Levels of Interleukin-6 (IL-6) And C-Reactive Protein (CRP) Preoperative as Predictors of the Output of Neurogenic Claudication Outcome Score (NCOS) 8 Weeks Post- Decompression-Stabilization-Fusion in Degenerative Lumbar Spinal Stenosis Patients
}

\author{
Nyoman Gede Bimantara ${ }^{1}$, I Ketut Suyasa ${ }^{2}$, I Gede Eka Wiratnaya ${ }^{2}$, \\ Iglna Artha Wiguna ${ }^{2}$, Elysanti Dwi Martadiani ${ }^{3}$, Marsha Ruthy Darmawan ${ }^{4}$ \\ ${ }^{1}$ Resident, Orthopedic and Traumatology Department, Faculty of Medicine Udayana University, RSUP. Sanglah \\ General Hospital, Bali. \\ ${ }^{2}$ Consultant, Orthopedic and Traumatology Department, Faculty of Medicine Udayana University, Sanglah \\ General Hospital, Denpasar, Bali. \\ ${ }^{3}$ Consultant, Radiology Department, Faculty of Medicine, Udayana University, Sanglah General Hospital, \\ Denpasar, Bali. \\ ${ }^{4}$ Resident, Radiology Department, Faculty of Medicine, Udayana University, Sanglah General Hospital, \\ Denpasar, Bali. \\ Corresponding Author: I Gede Eka Wiratnaya
}

DOI: https://doi.org/10.52403/ijhsr.20220120

\begin{abstract}
Introduction: Lumbar Spinal Stenosis (LSS) or spinal stenosis is the most common spinal disease in elderly patients. LSS is also one of the leading causes of spinal surgery in the world. The problem that is often encountered is the limited predictor of outcomes that are considered affordable and accurate, so as to provide education to patients about possible output after the surgery process is carried out. Therefore, a predictor is needed that is considered accurate and affordable such as the degree of measurable canal stenosis of Magnetic resonance imaging (MRI), serum levels of C-Reactive Protein (CRP) and Interleukin-6 (IL-6)

Method: This study used a prospective cohort design conducted to compare Neurogenic Claudication Outcome Score scores among people with degenerative lumbar canal stenosis whose postdecompression-stabilization-fusion had higher degrees of canal stenosis (measured through Schizas grading of Magnetic resonance Imaging/MRI) examinations), as well as high pre-operative CRP and IL-6 levels with those with normal CRP and IL-6 levels. From the population of lumbar spinal stenosis, the selection of samples was conducted consecutively sampling. After that, statistical tests in the form of descriptor tests, normality tests, risk factor assessments with $2 \times 2$ cross tabulation, and proportion comparison analysis using the Fisher Exact test.

Result: Severe lumbar canal stenosis degrees resulted in worse NCOS 8 weeks postoperative than mild degrees of lumbar canal stenosis, with statistically significant differences $(p=0.008 ; p<0.05)$ and RR 6.4 (0.99-41.08). High CRP levels resulted in worse NCOS 8 weeks postoperative than mild lumbar degrees of canal stenosis, with statistically significantly differences $(\mathrm{p}=0.008 ; \mathrm{p}<0.05)$ and RR 6.4 (0.99-41.08). High pre-operative IL-6 levels resulted in worse NCOS 8 weeks postoperative than normal pre-operative IL-6 levels with statistically significantly differences $(p=0.002 ; p<0.05)$ and RR 8 (1.24-51.50)
\end{abstract}


Nyoman Gede Bimantara et.al. Degrees of canal stenosis, levels of interleukin-6 (IL-6) and c-reactive protein (CRP) preoperative as predictors of the output of neurogenic claudication outcome score (NCOS) 8 weeks postdecompression-stabilization-fusion in degenerative lumbar spinal stenosis patients.

Conclusion: Degrees of preoperative (mild) canal stenosis, high pre-operative CRP levels, and high levels of pre-operative IL-6 were predictors for better 8-week NCOS scores in patients with postdecompression-stabilizing-fusion degenerative LSS disease.

Key Word: Degenerative lumbar spinal stenosis, IL-6, CRP, canal degree stenosis, NCOS

\section{INTRODUCTION}

Lumbar Spinal Stenosis (LSS) or spinal stenosis is the most common spinal disease in elderly patients. Spinal stenosis can be defined as narrowing of the spinal canal caused by mechanical compression of the nerve roots of the spine. LSS usually causes radicular pain, neurogenic intermittent claudication, and motor and sensory disorders of the lower extremities. LSS can occur congenitally or acquired, and degeneratively acquired LSS is by far the most common. Acquired stenosis is thought to result from a series of changes triggered by degeneration of the nucleus pulposus intervertebral disc as the patient ages. An accurate and affordable predictor such as the degree of measurable canal stenosis of Magnetic resonance imaging (MRI), serum levels of C-Reactive Protein (CRP) and Interleukin-6 (IL-6) are needed in managing lumbar spinal stenosis. ${ }^{1}$ Mechanical factors such as Schizas score, Oswestry disability index (ODI) and neurogenic claudication outcome score (NCOS) also plays a role in measuring canal stenosis. ${ }^{5}$

MRI examination is a noninvasive examination to evaluate the anatomy of the spine, specifically the structure of soft tissue in cases of lumbar stenosis. However, a discrepancy between MRI images and clinical symptoms is sometimes found in clinical practice. $^{2}$ Pain levels, walking capacity, and functional disabilities were not related to MRI parameters. LSS is a clinically correct syndrome with a complex relationship between radiological stenosis degrees and clinical manifestations, so radiological findings alone are not sufficiently the primary and only basis in the selection of therapies for lumbar stenosis. ${ }^{3}$ Local inflammation is also a part of the pain etiology in LSS. Inflammatory factors have been detected in the epidural space in patients with degenerative lumbar disorders and pain, including CRP and IL-6. CRP examination is one of the most sensitive inflammatory indicators in peripheral blood. LSS can be treated conventionally or surgically. For the treatment outcome, several functional outcome predictors have been proposed to dispel the functional output of LSS patients, such as Swiss Spinal Stenosis Questionnaire (SSSQ) and the use of Visual Analogue Scale (VAS).

This study aims to examine the role of mechanical factors (canal stenosis degrees) and inflammatory markers (CRP and IL-6) in patients with LSS as predictors of postoperative functional and clinical output, in the form of measurements of canal stenosis degrees, serum CRP and IL-6 levels.

\section{MATERIAL AND METHODS}

The study used a prospective cohort design conducted to compare Neurogenic Claudication Outcome Score scores between post-decompression-stabilization-fusion subjects with heavier degrees of lumbar canal stenosis degenerative disease compared to those with milder degrees, as well as high pre-operative CRP and IL-6 levels with normal levels of CRP and IL-6 from May to August 2021 with follow-up within 8 weeks. The study was conducted in the outpatient clinic and emergency unit of Sanglah Hospital, while decompressionstabilization-fusion will be carried out at Sanglah Hospital Central Surgical Installation. Patient follow-up was carried out at Orthopaedic outpatient clinic of Sanglah hospital.

Subjects' identity and information regarding previous medical history and comorbid disease were gathered from medical record or interview. Lumbar spinal 
Nyoman Gede Bimantara et.al. Degrees of canal stenosis, levels of interleukin-6 (IL-6) and c-reactive protein (CRP) preoperative as predictors of the output of neurogenic claudication outcome score (NCOS) 8 weeks postdecompression-stabilization-fusion in degenerative lumbar spinal stenosis patients.

stenosis diagnosis was made using MRI and the severity degree was based on the cerebrospinal fluid $(\mathrm{CSF}) /$ rootlet ratio as seen in the Axial image of $\mathrm{T} 2$ and arranged after observing different patterns corresponding to the rootlet that disappears inside the dural sac as the patient lies on his back during an MRI. The degree of canal stenosis is then divided into severe and mild degree stenosis. CRP and IL-6 level were obtained through laboratory examinations with ELISA technique. The decompressionstabilization-fusion surgery was done by combining (fusion) the spine or removing part of the disc. Stabilization measures are carried out through spinal instrumentation to enhance fusion and provide support for unstable areas of the spine. The functional outcome was assessed 8 weeks following the surgery, using Neurogenic Claudication Outcome Score (NCOS). The research protocol for Ethical Clearance from the Research Ethics Commission at the Faculty of Medicine, UNUD / Sanglah Hospital Denpasar was submitted before the research is carried out. Subjects were given an explanation of the purpose of the study and were asked to fill out written informed consent.
The samples were selected consequently based on inclusion and exclusion criteria. The inclusion criteria were as follows: (1) Diagnosed with degenerative lumbar canal stenosis based on the results of plain photo examination and magnetic resonance imaging (MRI); (2) Male or female gender; (3) Age 35-75 years; (4) Low back pain symptom does not improve with conservative therapy; (5) Planned and agreed to obtain decompression-stabilization-fusion measures. (6) Agree to participate in research. The exclusion criteria were: (1) Any acute and chronic infectious disease; (2) History of autoimmune disease; (3) Currently under any immunosuppressants or steroids medication; (4) History of spinal surgery; (5) Refused to participate in the study. The data analysis was done using $2 \times 2$ cross tabulation and calculated the size of the association in the form of Relative Risk (rR). Then comparison analysis was done using Chi-squared and Fisher's Exact test. Statistical Package for Social Sciences (SPSS) for Windows ${ }^{\circledR}$ version 24 program is used for data processing.

\section{RESULTS}

Table 1. Distribution of characteristics of the research subject

\begin{tabular}{|c|c|c|}
\hline Variable & n $(\%)$ & Mean \pm Standard Deviation \\
\hline Age (Year) & - & $57,5 \pm 8,26$ \\
\hline $\begin{aligned} & \text { Gender } \\
& \bullet \text { Male } \\
& \bullet \text { Female } \\
&\end{aligned}$ & $\begin{array}{c}6(33,33 \%) \\
12(66,77 \%) \\
\end{array}$ & - \\
\hline $\begin{array}{cl}\text { Degree of Canal stenosis } \\
\bullet & \text { Mild Degree (A-B) } \\
\text { - } & \text { Severe Degree (C-D) } \\
\end{array}$ & $\begin{array}{c}8(44,44 \%) \\
10(55,66 \%)\end{array}$ & - \\
\hline $\begin{array}{cl}\mathrm{IL}-6 & (\mathrm{pg} / \mathrm{ml}) \\
\bullet & \text { High }(>15 \mathrm{pg} / \mathrm{ml}) \\
\bullet & \text { Normal }(\leq 15 \mathrm{pg} / \mathrm{ml}) \\
\end{array}$ & $\begin{array}{l}9(50 \%) \\
9(50 \%)\end{array}$ & $14.87 \pm 14.15$ \\
\hline $\begin{array}{ll}\text { CRP } & (\mathrm{mg} / \mathrm{dL}) \\
\bullet & \text { High }(>5 \mathrm{mg} / \mathrm{dL}) \\
& \text { Normal }(\leq 5 \mathrm{mg} / \mathrm{dL}) \\
\text { Pathology } & \text { Level } \\
& \text { L1-L2 } \\
\bullet & \text { L2-L3 } \\
- & \text { L3-L4 } \\
\bullet & \text { L4-L5 } \\
\end{array}$ & $\begin{array}{c}10(55,6 \%) \\
8(44,4 \%) \\
4(9,76 \%) \\
9(21,95 \%) \\
12(29,27 \%) \\
16(39,02 \%)\end{array}$ & $7.72 \pm 8.64$ \\
\hline $\begin{array}{cc}8 \text { weeks NCOS Post-operative score } \\
\qquad \quad \text { Good }(>40) \\
\bullet \quad \operatorname{Bad}(\leq 40) \\
\end{array}$ & $\begin{array}{l}9(50 \%) \\
9(50 \%)\end{array}$ & $43.5 \pm 9.41$ \\
\hline
\end{tabular}

The distribution of characteristics of the research subject can be seen on Table 1 .
From descriptive analysis, a total of 18 patients with an average age of $57.5+8.26$ 
Nyoman Gede Bimantara et.al. Degrees of canal stenosis, levels of interleukin-6 (IL-6) and c-reactive protein (CRP) preoperative as predictors of the output of neurogenic claudication outcome score (NCOS) 8 weeks postdecompression-stabilization-fusion in degenerative lumbar spinal stenosis patients.

years and the sex of 6 men $(33.33 \%)$ and 12 women $(66.77 \%)$. Of the degrees of canal stenosis, there were 8 patients $(44.44 \%)$ with mild Schizas degrees (A and B) and 10 patients $(55.66 \%)$ with severe Schizas degrees. From the examination of IL-6 levels, the average level of IL-6 was $14.87+$ $14.15 \mathrm{pg} / \mathrm{ml}$ with details of 9 patients (50\%) high category and 9 patients (50\%) normal category. From the CRP examination, the average overall CRP level was $7.72+8.64 \mathrm{mg} / \mathrm{dL}$, with a division of 10 patients $(55.6 \%)$ including the high category and 8 patients $(44.4 \%)$ in the normal category. From the pathology level of canal stenosis, there are a total of 41 levels of pathology divided into 4 levels of L1-L2 (9.76\%), 9 levels of L1-L2 (21.95\%), 12 levels of L1-L2 (29.27\%), and 16 levels of L4-L5 (39.02\%). The average NCOS score of the study sample was $35.85+12.24$ with a division of 6 patients $(33.3 \%)$ good and 12 patients $(66.7 \%)$ bad. Because the study was case control, it selected 9 patients $(50 \%)$ in each group with a good and bad 8- week POST OP NCOS, with an average overall score of $43.5+9.41$.

Inferential analysis using Fisher's Exact test and RR calculation can be seen in table 2. Out of a total sample of 18 patients, there were 2 patients $(11.11 \%)$ with severe degree stenosis canals showing good postoperative NCOS scores, 8 patients $(44.44 \%)$ with severe degree stenosis canals showing poor postoperative 8 weeks of NCOS scores, 7 patients (38.89\%) with mild degree stenosis canals showing NCOS scores 8 weeks post-surgery. and 1 patient $(5.6 \%)$ with mild degree stenosis canal showed a poor 8-week postoperative NCOS score. Severe degrees of lumbar canal stenosis result in worse NCOS 8 weeks postoperative than mild lumbar canal stenosis degrees, with statistically significant difference. Follow-up analysis obtained a Relative Risk (RR) of 6.4 (0.9941.08) so that patients with severe lumbar canal stenosis were 6.4 times more likely to produce poor NCOS scores 8 weeks postoperatively compared to populations with mild lumbar canal stenosis degrees.

\begin{tabular}{|c|c|c|c|c|}
\hline \multirow[t]{2}{*}{ Variable } & \multicolumn{2}{|c|}{8 weeks post operative NCOS } & \multirow[b]{2}{*}{ P value } & \multirow{2}{*}{$\begin{array}{c}\text { RR } \\
(95 \% \text { IK) }\end{array}$} \\
\hline & Bad (Skor < 40) & Good (Skor > 40) & & \\
\hline $\begin{array}{cc}\text { Degrees of Canal Stenosis } \\
\bullet & \text { Severe }(\mathrm{C}+\mathrm{D}) \\
\bullet & \text { Mild }(\mathrm{A}+\mathrm{B}) \\
\end{array}$ & $\begin{array}{c}8(44,4 \%) \\
1(5,6 \%)\end{array}$ & $\begin{array}{l}2(11,1 \%) \\
7(38,9 \%) \\
\end{array}$ & 0,008 & $\begin{array}{c}6,4 \\
(0,99-41,08)\end{array}$ \\
\hline
\end{tabular}

Out of a total sample of 18 patients, there were 2 patients $(11.11 \%)$ with high pre-operative CRP levels showing good postoperative 8 weeks of NCOS scores, 8 patients $(44.44 \%)$ with high pre-operative CRP levels showing poor postoperative 8week NCOS scores, 7 patients $(38.89 \%)$ with normal pre-operative CRP levels showing good postoperative 8-week NCOS scores, and 1 patient $(5.56 \%)$ with normal pre-operative CRP levels showed a poor 8- week postoperative NCOS score. High CRP result shows in worse NCOS score 8 week post-operatively than mild lumbar degrees of canal stenosis. Follow-up analysis obtained a Relative Risk (RR) of 6.4 (0.9941.08) so that patients with high preoperative CRP levels had a 6.4-fold chance of producing poor post-operative NCOS values compared to populations with normal pre-operative CRP levels as seen in Table 3.

Table 3. Fisher's Exact test and RR Calculation of CRP Level

\begin{tabular}{|c|c|c|c|c|}
\hline \multirow{2}{*}{ Variable } & \multicolumn{2}{|c|}{ 8 weeks post operative NCOS } & & RR \\
\cline { 2 - 4 } & Bad (Skor < 40) & Good (Skor > 40) & P Value & (95\% IK) \\
\hline Pre-operative CRP & & & & \\
• High & $8(44,4 \%)$ & $2(11,1 \%)$ & 0,008 & 6,4 \\
- Normal & $1(5,6 \%)$ & $7(38,9 \%)$ & & $(0,99-41,08)$ \\
\hline
\end{tabular}

Out of a total sample of 18 patients, there was 1 patient $(5.6 \%)$ with high pre- operative IL-6 levels showing a good postoperative 8 -week NCOS score, 8 
Nyoman Gede Bimantara et.al. Degrees of canal stenosis, levels of interleukin-6 (IL-6) and c-reactive protein (CRP) preoperative as predictors of the output of neurogenic claudication outcome score (NCOS) 8 weeks postdecompression-stabilization-fusion in degenerative lumbar spinal stenosis patients.

patients $(44.44 \%)$ with high pre-operative IL-6 levels showing a poor postoperative 8week NCOS score, 8 patients $(44.44 \%)$ with normal pre-operative IL-6 levels showing good postoperative 8-week NCOS values, and 1 patient $(5.56 \%)$ with normal preoperative IL-6 levels showed a poor 8-week postoperative NCOS score

High pre-operative IL-6 levels result in worse NCOS 8 weeks postoperative than normal pre-operative IL-6 levels with statistically meaningful differences $(\mathrm{p}=0.002 ; \mathrm{p}<0.05)$. Follow-up analysis found a Relative Risk (RR) of 8 (1.2451.50) so that patients with high levels of pre-operative IL- 6 were 8 times more likely to produce poor postoperative NCOS values compared to populations with normal preoperative IL-6 levels, as seen in Table 4.

\begin{tabular}{|c|c|c|c|c|}
\hline \multirow[t]{2}{*}{ Variable } & \multicolumn{2}{|c|}{8 weeks Post-operative NCOS } & \multirow[b]{2}{*}{ P value } & \multirow{2}{*}{$\begin{array}{c}\text { RR } \\
(95 \% \text { IK) }\end{array}$} \\
\hline & Bad (Skor < 40) & Good (Skor > 40) & & \\
\hline $\begin{array}{cc}\text { Preoperative IL-6 } \\
\text { • } & \text { High }(>15 \mathrm{pg} / \mathrm{mL}) \\
\bullet & \text { Normal }(<15 \mathrm{pg} / \mathrm{mL})\end{array}$ & $\begin{array}{c}8(44,4 \%) \\
1(5,6 \%)\end{array}$ & $\begin{array}{c}1(5,6 \%) \\
8(44,4 \%)\end{array}$ & 0,002 & $\begin{array}{c}8 \\
(1,24-51,50)\end{array}$ \\
\hline
\end{tabular}

\section{DISCUSSION}

Based on the study, it was found that patients aged 71-80 years had the greatest chance of experiencing lumbar canal stenosis, which is as many as $30 \%$ of cases (20 out of a total of 60 cases). Judging by the sex variables, the majority of patients in the study were women (12 patients, 66.7\%). A systematic review study and metaanalysis by Jensen et al. showed that 26 of the 48 studies that delivered characteristic distribution by gender $(54.17 \%)$ were the majority of women. Judging from the pathology level variables, it was found that the majority of patients in this study had pathology at L4-L5 levels (16 patients, $39.02 \%)$. This finding is in line with previous research by Ishfaq et al. who found that the incidence of lumbar canal stenosis was at L4-L5 levels as much as $51.67 \%$ of cases (31 out of a total of 60 cases In addition to the above, judging from the variable degree of canal stenosis, IL-6 levels, and CRP levels, researchers wanted to convey that the distribution of patients with these 3 variables are fairly even. This is evidenced by the comparison of patients with severe canal stenosis degrees and high CRP levels of $55.6 \%$ (10 patients) each while patients with mild canal stenosis degrees and normal CRP levels amounted to $44.44 \%$ (8 patients) each. In fact, judging from the variable IL-6 levels, it was found that $50 \%$ (9 patients) had high LEVELS of
IL-6 while 50\% (9 patients) others had normal IL-6 level. ${ }^{54,59}$

It was found that NCOS is responsive to assessing the clinical exterior of patients with lumbar canal stenosis. NCOS was developed by Weiner and Fraser to assess neurogenic claudication. Over time, NCOS is also used to assess clinical externality in patients with lumbar canal stenosis. Scoring using NCOS is considered easy, precise, and can be used by patients. NCOS consists of 8 questions (16 items) with a final value range of 0 to 100 . The higher the final score indicates the patient has a good clinical outcome. Our results are in line with previous studies by Suyasa et al. which measured the functional score and validity of NCOS in LSS. This can be because heavier degrees of stenosis represent a heavier mechanical cause making it harder to achieve a good postoperative NCOS score. However, some other factors need to be considered, such as other accompanying diseases that can obscure the patient's overall daily functioning. ${ }^{60}$

To date, there have been few references describing the relationship between the degree of severe stenosis canal and the functional externality of the NCOS score. Many of these references only describe the findings descriptively. Therefore, the reason why severe canal stenosis levels result in low NCOS scores is associated with the pathophysiology of the 
Nyoman Gede Bimantara et.al. Degrees of canal stenosis, levels of interleukin-6 (IL-6) and c-reactive protein (CRP) preoperative as predictors of the output of neurogenic claudication outcome score (NCOS) 8 weeks postdecompression-stabilization-fusion in degenerative lumbar spinal stenosis patients.

canal stenosis itself. In most cases, canal stenosis is mostly caused by degenerative causes or changes in arthritis in the discs, ligaments, or facet joints around the lumbar canal. These changes include hypertrophy in the cartilage part of the joint, disc herniation, hypertrophy of the flavum ligament, and osteophyte formation. ${ }^{61}$ The results in our study are not in accordance with previous research conducted by Ishfaq et al. (2020) in 60 patients with varying degrees of canal stenosis (mild, moderate, and severe) that connected the functional range of NCOS scores.

In this study, CRP examination was carried out because it was found to increase in acute inflammatory conditions. Sugimori et al found that average CRP levels in individuals with herniation in the intervertebral disc were higher than in normal individuals. Studies conducted by Fukushi et al showed that high third- and seventh-day post-operative CRP levels had lower NCOS score scores in patients with post-decompression-stabilization-fusion

LSS. It is caused by a major inflammatory response that occurs in patients. However, it can also indicate complications of infection in patients. While high preoperative CRP levels can result in lower NCOS score values due to CRP levels not only punching the number of damaged networks but also the type of network that is damaged. Contrary to our results and explanations above, a study conducted by Rajasekaran et al. (2013) showed that increased levels of pre-operative and post-operative CRP first and third day resulted in an increase in NCOS values with an average increase from 26.32 to 62.75 in patients with postdecompressant-stabilization and fusion LSS. These results are supported by research conducted by Kurisu et al, there is a postoperative CRP increase that increases the value of NCOS. However, this can be suspected by another factor, namely the balance of glucose tolerance in patients. ${ }^{63-66}$

In the exposure of previous results it can be observed that in this study found high levels of pre-operative IL-6 in patients with degenerative LSS will give NCOS $\begin{array}{llll}\text { values } & 8 & \text { weeks post-surgery }\end{array}$ docompression-stabilization-fusion is low, and this proves statistically meaningful $(\mathrm{p}=$ 0.002 ). The study also found that preoperative IL-6 levels within the normal range in patients with degenerative LSS would provide high NCOS values as evidenced by the high number of samples ( $p$ $=0.002$ ). This suggests that patients with high pre-operative IL-6 levels will produce low NCOS scores in degenerative LSS patients 8 weeks post-docompressionstabilization-fusion surgery. There have been several other studies that have observed high levels of IL-6 in patients with degenerative lumbar disorders. This is in line with research conducted by Weber et al, which explained that there was an increase in IL-6 levels in patients with degenerative lumbar disorder. Khan et al in his study also stated that there was an increase in IL-6 levels in patients with degenerative lumbar. ${ }^{60-61}$

\section{CONCLUSION}

From this study, it can be concluded that preoperative mild canal stenosis degrees were a predictor for better 8-week NCOS score in patients with postdecompression-stabilization-fusion degenerative LSS disease, meanwhile high IL-6 and CRP level are predictor for lower 8-week NCOS score.

\section{ACKNOWLEDGEMENTS}

We would like to thank Ketut Gede Mulyadi Ridia as Head of Orthopaedics and Traumatology Department, Faculty of Medicine Udayana University, Sanglah General Hospital for all the support regarding this study.

Funding: The author is responsible for funding this study without involving sponsors, grants, and various other funding sources.

Conflict of Interest: The author states that there is no conflict of interest related to the material discussed in the manuscript. 
Nyoman Gede Bimantara et.al. Degrees of canal stenosis, levels of interleukin-6 (IL-6) and c-reactive protein (CRP) preoperative as predictors of the output of neurogenic claudication outcome score (NCOS) 8 weeks postdecompression-stabilization-fusion in degenerative lumbar spinal stenosis patients.

Ethical Approval: The research protocol for Ethical Clearance from the Research Ethics Commission at the Faculty of Medicine, UNUD / Sanglah Hospital Denpasar will be submitted before the research is carried out. Subjects who met the study criteria were given an explanation of the purpose of the study and were asked to fill out written informed consent. Researchers have also attached a secondary data collection permit in the form of a medical record at Sanglah Hospital Denpasar

Authors' Contribution: Nyoman Gede Bimantara is responsible for finding research samples, implementing actions, and analyzing data, and reporting on research results. I Gede Eka Wiratnaya, I Ketut Suyasa, IGLNA Artha Wiguna, were responsible for the research design concept and the supervisor in this study.

\section{REFERENCES}

1. Wu A-M, Zou F, Cao Y, et al. Lumbar spinal stenosis: an update on the epidemiology, diagnosis and treatment. AME Med J. Epub ahead of print 2017. DOI: 10.21037/amj.2017.04.13.

2. Ambade RE, Mane KK. Clinical evaluation of lumbar spinal stenosis and its correlation with the MRI findings. Indian J Orthop Surg. Epub ahead of print 2016. DOI: 10.5958/2395-1362.2016.00054.2.

3. Andrasinova T, Adamova B, Buskova J, et al. Is there a correlation between degree of radiologic lumbar spinal stenosis and its clinical manifestation? Clin Spine Surg. Epub ahead of print 2018. DOI: 10.1097/BSD.0000000000000681.

4. Mannion AF, Fekete TF, Pacifico D, et al. Dural sac cross-sectional area and morphological grade show significant associations with patient-rated outcome of surgery for lumbar central spinal stenosis. Eur Spine J. Epub ahead of print 2017. DOI: 10.1007/s00586-017-5280-7.

5. Prasetya AIP, Gardjito FB, Prijosedjati RA, et al. Correlation between Schizas Score, Degree of Disability, and Neurogenic Claudication in Lumbar Spinal Stenosis. Indones J Med. Epub ahead of print 2019. DOI: 10.26911/theijmed.2019.04.02.05.
6. Sugimori K, Kawaguchi Y, Morita M, et al. High-sensitivity analysis of serum Creactive protein in young patients with lumbar disc herniation. J Bone Jt Surg - Ser B. Epub ahead of print 2003. DOI: 10.1302/0301-620X.85B8.14538.

7. Elkan P, Sten-Linder M, Hedlund R, et al. Markers of inflammation and fibrinolysis in relation to outcome after surgery for lumbar disc herniation. A prospective study on 177 patients. Eur Spine J. Epub ahead of print 2016. DOI: 10.1007/s00586-015-3998-7.

8. Igarashi A, Kikuchi SI, Konno SI. Correlation between inflammatory cytokines released from the lumbar facet joint tissue and symptoms in degenerative lumbar spinal disorders. J Orthop Sci. Epub ahead of print 2007. DOI: 10.1007/s00776006-1105-y.

9. Covaro A, Vilà-Canet $\mathrm{G}$, de Frutos AG, et al. Management of degenerative lumbar spinal stenosis: An evidence-based review. EFORT Open Rev. Epub ahead of print 2016. DOI: $10.1302 / 2058-5241.1 .000030$.

10. Kreiner DS, Shaffer WO, Baisden JL, et al. An evidence-based clinical guideline for the diagnosis and treatment of degenerative lumbar spinal stenosis (update). Spine J. Epub ahead of print 2013. DOI: 10.1016/j.spinee.2012.11.059.

11. Ježek $J$, Waldauf $P$, Krbec $M$, et al. Outcomes and Complications of Surgical Treatment for LSS at 1-Year Follow-up Prospective Study. Acta Chir Orthop Traumatol Cech. 2019;86(4):256-263. Czech. PMID: 31524586.

12. Mattei TA, Goulart CR, Milano JB, et al. Cervical Spondylotic Myelopathy: Pathophysiology, Diagnosis, and Surgical Techniques. ISRN

13. Neurol. Epub ahead of print 2011. DOI: 10.5402/2011/463729.

14. Blom A, Warwick D, Whitehouse M. Apley \& Solomon's System of Orthopaedics and Trauma. 10th editi. New York: CRC Press, 2017.

15. Kim YU, Kong YG, Lee J, et al. Clinical symptoms of lumbar spinal stenosis associated with morphological parameters on magnetic resonance images. Eur Spine J. Epub ahead of print 2015. DOI: 10.1007/s00586-015-4197-2.

16. Bydon M, Alvi MA, Goyal A. Degenerative Lumbar Spondylolisthesis: Definition, Natural History, Conservative Management, 
Nyoman Gede Bimantara et.al. Degrees of canal stenosis, levels of interleukin-6 (IL-6) and c-reactive protein (CRP) preoperative as predictors of the output of neurogenic claudication outcome score (NCOS) 8 weeks postdecompression-stabilization-fusion in degenerative lumbar spinal stenosis patients.

and Surgical Treatment. Neurosurgery Clinics of North America. Epub ahead of print 2019. DOI: 10.1016/j.nec.2019.02.003.

17. Harry Herkowitz, Steven Garfin, Frank Eismont, et al. Rothman-Simeone The Spine - 6th Edition. ELSEVIER.

18. Miller MD, R. TS. Miller's Review of orthopaedics. Journal of Chemical Information and Modeling.

19. Thomé C, Börm W, Meyer F. Degenerative Lumbar Spinal Stenosis - Current Strategies in Diagnosis and Treatment. Dtsch Aerzteblatt Online. Epub ahead of print 2008. DOI: 10.3238/arztebl.2008.0373.

20. Ammendolia C. Degenerative lumbar spinal stenosis and its imposters: Three case studies. J Can Chiropr Assoc.

21. Kalichman L, Cole R, Kim DH, et al. Spinal stenosis prevalence and association with symptoms: the Framingham Study. Spine J. Epub ahead of print 2009. DOI: 10.1016/j.spinee.2009.03.005.

22. Fortin M, Lazáry À, Varga PP, et al. Association between paraspinal muscle morphology, clinical symptoms and functional status in patients with lumbar spinal stenosis. Eur Spine J. Epub ahead of print 2017. DOI: 10.1007/s00586-017-5228$\mathrm{y}$.

23. Yoshida M, Shima K, Taniguchi Y, et al. Hypertrophied ligamentum flavum in lumbar spinal canal stenosis: Pathogenesis and morphologic and immunohistochemical observation. Spine (Phila Pa 1976). Epub ahead of print 1992. DOI: 10.1097/00007632-199211000-00015.

24. Schroeder GD, Kurd MF, Vaccaro AR. Lumbar spinal stenosis: How is it classified? Journal of the American Academy of Orthopaedic Surgeons. Epub ahead of print 2016. DOI: 10.5435/JAAOS-D-15-00034.

25. Parker SL, Godil SS, Mendenhall SK, et al. Two-year comprehensive medical management of degenerative lumbar spine disease (lumbar spondylolisthesis, stenosis, or disc herniation): A value analysis of cost, pain, disability, and quality of life: Clinical article. J Neurosurg Spine. Epub ahead of print 2014. DOI: 10.3171/2014.3.SPINE1320.

26. Yabe Y, Hagiwara Y, Ando A, et al. Chondrogenic and Fibrotic Process in the Ligamentum Flavum of Patients with Lumbar Spinal Canal Stenosis. Spine (Phila
$\mathrm{Pa}$ 1976). Epub ahead of print 2015. DOI: 10.1097/BRS.0000000000000795.

27. Battié MC, Ortega-Alonso A, Niemelainen $\mathrm{R}$, et al. Brief report: Lumbar spinal stenosis is a highly genetic condition partly mediated by disc degeneration. Arthritis Rheumatol. Epub ahead of print 2014. DOI: 10.1002/art.38823.

28. Tomkins-Lane CC, Battié MC, Hu R, et al. Pathoanatomical characteristics of clinical lumbar spinal stenosis. Journal of Back and Musculoskeletal Rehabilitation. Epub ahead of print 2014. DOI: 10.3233/BMR-130440.

29. Lurie J, Tomkins-Lane C. Management of lumbar spinal stenosis. BMJ (Online). Epub ahead of print 2016. DOI: 10.1136/bmj.h6234.

30. Siebert E, Prüss $H$, Klingebiel $R$, et al. Lumbar spinal stenosis: Syndrome, diagnostics and treatment. Nature Reviews Neurology. Epub ahead of print 2009. DOI: 10.1038/nrneurol.2009.90.

31. Choi Y-S. Pathophysiology of Degenerative Disc Disease. Asian Spine J. Epub ahead of print 2009. DOI: 10.4184/asj.2009.3.1.39.

32. Katz JN, Dalgas M, Stucki G, et al. Degenerative lumbar spinal stenosis diagnostic value of the history and physical examination. Arthritis Rheum. Epub ahead of print $1995 . \quad$ DOI: 10.1002/art.1780380910.

33. Chad DA. Lumbar Spinal Stenosis. Neurologic Clinics. Epub ahead of print 2007. DOI: 10.1016/j.ncl.2007.01.003.

34. Schizas C, Theumann N, Burn A, et al. Qualitative grading of severity of lumbar spinal stenosis based on the morphology of the dural sac on magnetic resonance images. Spine (Phila Pa 1976). Epub ahead of print 2010.

DOI: 10.1097/BRS.0b013e3181d359bd.

35. Bagley C, Macallister M, Dosselman L, et al. Current concepts and recent advances in understanding and managing lumbar spine stenosis [version 1; referees: 3 approved]. F1000Research. Epub ahead of print 2019. DOI: 10.12688/f1000research.16082.1.

36. Shah JM, Gritsenko K, Wahezi SE. Degenerative lumbar spinal stenosis. In: Pain Medicine: An Essential Review. 2017. Epub ahead of print 2017. DOI: 10.1007/978-3-319-43133-8_122.

37. Weber C, Lønne G, Rao V, et al. Surgical management of lumbar spinal stenosis: a survey among Norwegian spine surgeons. 
Nyoman Gede Bimantara et.al. Degrees of canal stenosis, levels of interleukin-6 (IL-6) and c-reactive protein (CRP) preoperative as predictors of the output of neurogenic claudication outcome score (NCOS) 8 weeks postdecompression-stabilization-fusion in degenerative lumbar spinal stenosis patients.

Acta Neurochir (Wien). Epub ahead of print 2017. DOI: 10.1007/s00701-016-3020-0.

38. Overdevest GM, Jacobs W, VleggeertLankamp C, et al. Effectiveness of posterior decompression techniques compared with conventional laminectomy for lumbar stenosis. Cochrane Database of Systematic Reviews. Epub ahead of print 2015. DOI: 10.1002/14651858.CD010036.pub2.

39. Mobbs RJ, Li J, Sivabalan P, et al. Outcomes after decompressive laminectomy for lumbar spinal stenosis: Comparison between minimally invasive unilateral laminectomy for bilateral decompression and open laminectomy: Clinical article. J Neurosurg Spine. Epub ahead of print 2014. DOI: 10.3171/2014.4.SPINE13420.

40. Shanno G. Rothman-Simeone: The Spine. Neurosurgery. Epub ahead of print 2000. DOI: 10.1227/00006123-200007000-00057.

41. Ehlers S, Kaufmann SHE. Infection, inflammation, and chronic diseases: consequences of a modern lifestyle. Trends Immunol. Epub ahead of print 2010. DOI: 10.1016/j.it.2010.02.003.

42. Stables MJ, Gilroy DW. Old and new generation lipid mediators in acute inflammation and resolution. Progress in Lipid Research. Epub ahead of print 2011. DOI: 10.1016/j.plipres.2010.07.005.

43. Aggerholm-Pedersen N, Maretty-Kongstad $\mathrm{K}$, Keller J, et al. The prognostic value of serum biomarkers in localized bone sarcoma. Transl Oncol. Epub ahead of print 2016. DOI: 10.1016/j.tranon.2016.05.006.

44. Li W, Luo X, Liu Z, et al. Prognostic value of C-reactive protein levels in patients with bone neoplasms: A meta-analysis. PLoS One. Epub ahead of print 2018. DOI: 10.1371/journal.pone.0195769.

45. Lee S, Choe J-W, Kim H-K, et al. HighSensitivity C-Reactive Protein and Cancer. J Epidemiol 2011; 21: 161-168.

46. Tanaka T, Narazaki M, Kishimoto T. Il-6 in inflammation, Immunity, And disease. Cold Spring Harb Perspect Biol. Epub ahead of print 2014.2 DOI: 10.1101/cshperspect.a016295.

47. Douraiswami B, Dilip PK, Harish BN, et al. C-reactive protein and interleukin-6 levels in the early detection of infection after open fractures. J Orthop Surg (Hong Kong). Epub ahead of print 2012. DOI: $10.1177 / 230949901202000325$.
48. Azimi P, Mohammadi HR, Montazeri A. An outcome measure of functionality in patients with lumber spinal stenosis: a validation study of the Iranian version of Neurogenic Claudication Outcome Score (NCOS). BMC Neurol. Epub ahead of print 2012. DOI: 10.1186/1471-2377-12-101.

49. Stürmer T, Raum E, Buchner M, et al. Pain and high sensitivity $C$ reactive protein in patients with chronic low back pain and acute sciatic pain. Ann Rheum Dis. Epub ahead of print 2005. DOI: 10.1136/ard.2004.027045.

50. Peng B, DePalma MJ. Cervical disc degeneration and neck pain. J Pain Res. Epub ahead of print 2018. DOI: 10.2147/JPR.S180018.

51. Okada S. The pathophysiological role of acute inflammation after spinal cord injury. Inflammation and Regeneration. Epub ahead of print 2016. DOI: $10.1186 / \mathrm{s} 41232-$ 016-0026-1.

52. Yu Z, Sun X, Xia R, et al. Modulation of inflammatory factors predicts the outcome following spinal cord injury. J Orthop Surg Res. Epub ahead of print 2020. DOI: 10.1186/s13018-020-01727-1.

53. Mustafa Sirvanci, Mona Bhatia, Kursat Ali Ganiyusufoglu, Cihan Duran, Mehmet Tezer CO, Hamzaoglu, Mehmet Aydogan A. Degenerative lumbar spinal stenosis: correlation with Oswestry Disability Index and MR Imaging. 2008; 679-685.

54. Hurri H, Slätis $P$, Soini J, et al. Lumbar spinal stenosis: Assessment of long-term outcome 12 years after operative and conservative treatment. J Spinal Disord. Epub ahead of print 1998. DOI: 10.1097/00002517-199804000-00003.

55. Ishfaq A, Shahzad M, Bashir Q, et al. Correlation Between Clinical Neurogenic Claudication Outcome Score (NCOS) And Radiological Grading of Lumbar Spinal Stenosis on Magnetic Resonance Imaging Lumbosacral Spine. Pak Armed Forces Med J 2020; 70: 1506-10.

56. Yuan S, Zou Y, Li Y, et al. A clinically relevant MRI grading system for lumbar central canal stenosis. Clin Imaging. Epub ahead of print 2016. DOI: 10.1016/j.clinimag.2016.07.005.

57. Marawar S V., Ordway NR, Madom IA, et al. Comparison of Surgeon Rating of Severity of Stenosis Using Magnetic Resonance Imaging, Dural Cross-Sectional 
Nyoman Gede Bimantara et.al. Degrees of canal stenosis, levels of interleukin-6 (IL-6) and c-reactive protein (CRP) preoperative as predictors of the output of neurogenic claudication outcome score (NCOS) 8 weeks postdecompression-stabilization-fusion in degenerative lumbar spinal stenosis patients.

Area, and Functional Outcome Scores. World Neurosurg. Epub ahead of print 2016. DOI: 10.1016/j.wneu.2016.08.093.

58. Farrokhi MR, Yadollahikhales G, Gholami M. Treatment of 44 Cases With Lumbar Spine Stenosis and Degenerative Instability: Outcomes of Surgical Intervention. Iran J Neurosurg. Epub ahead of print 2017. DOI: 10.29252/irjns.3.3.79.

59. Younan M, Atkinson TJ, Fudin J. A Practical Approach to Discontinuing NSAID Therapy Prior to a Procedure. Pract Pain Manag 2013; 13: 45-51.

60. Jensen RK, Jensen TS, Koes B, et al. Prevalence of lumbar spinal stenosis in general and clinical populations: a systematic review and meta-analysis. Eur Spine J 2020; 29: 2143-2163.

61. Suyasa IK, Adiwardhana IGS, Setiawan IGY. A comparison of neurogenic claudication outcome score and oswestry disability index in degenerative lumbar spinal canal stenosis post decompression, posterior stabilization and fusion. Int $\mathbf{J}$ Orthop Sci 2018; 4: 409-411.

62. Alvarez JA, Hardy RH. Lumbar spine stenosis: A common cause of back and leg pain. American Family Physician.

63. Zileli M, Crostelli M, Grimaldi M, et al. Natural Course and Diagnosis of Lumbar Spinal Stenosis: WFNS Spine Committee Recommendations. World Neurosurg X 2020; 7: 100073.

64. Park $\mathrm{CH}$, Lee SH. Investigation of HighSensitivity C-reactive Protein and Erythrocyte Sedimentation Rate in Low Back Pain Patients. Korean J Pain. Epub ahead of print 2010. DOI: 10.3344/kjp.2010.23.2.147.

65. Fukushi R, Yoshimoto M, Iesato N, et al. Short-term Results of Microendoscopic Muscle-preserving Interlaminar Decompression versus Spinal Process Splitting Laminectomy. J Neurol Surgery, Part A Cent Eur Neurosurg. Epub ahead of print 2018. DOI: 10.1055/s-0037-1608871.

66. Rajasekaran S, Thomas A, Kanna RM, et al. Lumbar spinous process splitting decompression provides equivalent outcomes to conventional midline decompression in degenerative lumbar canal stenosis: A prospective, randomized controlled study of 51 patients. Spine (Phila Pa 1976). Epub ahead of print 2013. DOI: 10.1097/BRS.0b013e3182a056c1.

67. Kurisu K, Tsurutani Y, Inoue K, et al. Intraindividual association between C-reactive protein and insulin administration in postoperative lumbar spinal canal stenosis patients: A retrospective cohort study. J Diabetes Investig 2020; 11: 980-984.

68. Holm S, Mackiewicz Z, Holm AK, et al. Pro-inflammatory, pleiotropic, and antiinflammatory TNF- $\alpha$, IL-6, and IL-10 in experimental porcine intervertebral disk degeneration. Vet Pathol 2009; 46: $1292-$ 1300.

69. Yukawa Y, Lenke LG, Tenhula J, et al. A comprehensive study of patients with surgically treated lumbar spinal stenosis with neurogenic claudication. J Bone Jt Surg - Ser A 2002; 84: 1954-1959.

70. Sasai K, Umeda M, Maruyama $T$, et al. Microsurgical bilateral decompression via a unilateral approach for lumbar spinal canal stenosis including degenerative spondylolisthesis: Clinical article. J Neurosurg Spine 2008; 9: 554-559.

71. Weber KT, Alipui DO, Sison CP, et al. Serum levels of the proinflammatory cytokine interleukin-6 vary based on diagnoses in individuals with lumbar intervertebral disc diseases. Arthritis Res Ther. Epub ahead of print 2016. DOI: 10.1186/s13075-015-0887-8.

72. Khan AN, Jacobsen HE, Khan J, et al. Inflammatory biomarkers of low back pain and disc degeneration: a review. Ann N Y Acad Sci 2017; 1410: 6884.10.1002/jcp.22402.

How to cite this article: Nyoman Gede Bimantara, I Ketut Suyasa, I Gede Eka Wiratnaya et.al. Degrees of canal stenosis, levels of interleukin-6 (IL-6) and c-reactive protein (CRP) preoperative as predictors of the output of neurogenic claudication outcome score (NCOS) 8 weeks post-decompressionstabilization-fusion in degenerative lumbar spinal stenosis patients. Int J Health Sci Res. 2022; 12(1):137-146. DOI: https://doi.org/10. 52403/ijhsr.20220120 